\title{
Collaborative Control of Supply Chain Risk in Big Data Environment
}

\author{
De-Yi DAI \\ Jiangsu Vocational Institute of Commerce, PR. China \\ Corresponding author
}

\begin{abstract}
In the new technology environment, the mode of operation of the supply chain has changed. Big data creates new value for the operation of the supply chain, enhances the efficiency of information transmission in the supply chain, and increases the production profit of the enterprise. This paper analyzes the operation mode of the supply chain in the big data environment and compares it with the traditional supply chain. Based on this, the article analyzes the risk factors of supply chain operation, and expounds the sources of these risk factors, and puts forward the prevention of supply chain prevention risks. This paper has practical significance for the application of big data technology in the supply chain.
\end{abstract}

Keywords: supply chain, big data, risk, control

\section{Introduction}

The continuous development of big data provides a further basis for enterprises to implement scientific decision-making. By collecting the comprehensive operation data of the supply chain, integrating the polymorphic and heterogeneous data generated inside and outside the supply chain, using the advanced distributed database system to conceal the hidden data relationships and predict the behavior of supply chain members to achieve data-driven decision-making. Building supply chain based on big data is the inevitable trend of supply chain management.

In the field of supply chain risk management, many domestic scholars in recent years conducted in-depth research. Chen Ke-jia et al. (2016) considered the risk of supply chain disruption and put forward the optimal quantity decision method of supply chain. Fan Xing (2016) and others based on the fuzzy theory, identified the risk of transnational agricultural supply chain, put forward a set of multi-attribute risk assessment model. Nie Rui-fang (2016) analyzes the supply chain risk of $\mathrm{O} 2 \mathrm{O}$ model, and puts forward the risk prevention strategy of supply chain in this model. Sun Jin-hua (2017) and others put forward a method to identify the risk factors of science and technology service supply chain. Based on the social network analysis model, the risk is identified and evaluated. Yan Jie et al. (2017) analyzed the present situation of supply chain risk management and proposed the definition of supply chain risk from the perspective of market economy. Mu-jing et al. (2017) analyzed the supply chain of agricultural products based on the Internet of Things, and divided the risk into the sensing layer, the information layer and the application layer, and put forward the corresponding strategy.

In summary, the current research on the management of supply chain risk involves all aspects of the supply chain, most of the research from the risk of the mechanism, to deal with the risk of strategic aspects, but the development of big data supply chain has gradually mature, The risk of the existence of big data supply chain, there is no scholar for a profound analysis, this paper will be the existence of big data supply chain to identify the risk, combined with the risk of the mechanism, put forward the relevant control measures.

\section{Risk Factors Identification in Big data Supply Chain}

Building a big data supply chain is currently the hottest topic in the field of supply chain management, however, most companies will focus more on the use of big data technology to improve the efficiency of supply chain operations and reduce the total cost of the supply chain, thus ignoring the potential risks of big data supply chain, and the rapid development of mobile Internet, online payment, the response time put forward higher requirements for supply chain management, timely delivery, low inventory, global procurement have greatly increased the risk of supply chain.

In addition, the global procurement makes the supply chain become more and more complex and complex, many companies are gradually outsourced non-core business, the supply chain participants are mixed, big data also make the supply chain operations become more streamlined, which are making the big data supply chain more vulnerable to the impact of emergencies, and face a higher risk.

The operation mode of the big data supply chain is different from the traditional supply chain, so the risk of big data is also different from the traditional supply chain, as shown in Figure 2-1. The traditional supply chain is "a flow" mode of operation, from the supply segment to the demand side, the end of the sales forecast information from the bottom up to pass, front-end production information from top to bottom level. And the forecast of big data supply chain occurs in all aspects of the operation process. The production plan of each link is driven by big data forecasting information. On the aspect of information transmission, the forecast information is uploaded to the supply chain big data platform. And other enterprises can obtain information from the big data platform, so it's alleviates the bullwhip effect effectively. As the big data technology can capture the unstructured information in the process of supply chain operation, therefore, at the link of sales of the supply chain, customers' needs are more detailed split, the supply chain can develop a more accurate marketing strategy, Figure $2-1$ is a clear expression of the operation of big data supply chain process. 


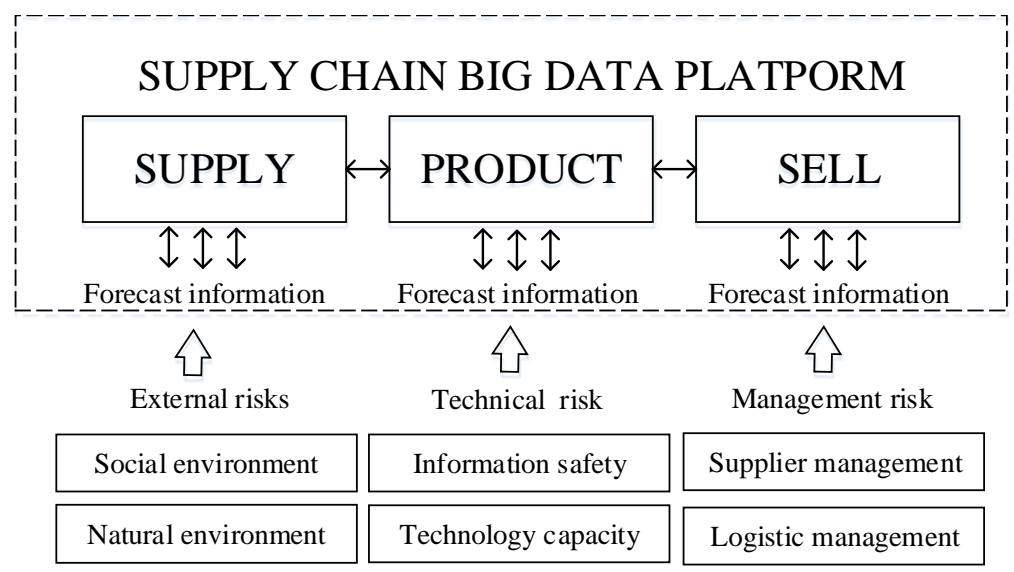

Figure 2-1 The risk factors of big data supply chains

The sources of risk factors of big data supply chain have a wide range, there are three main areas, external environmental risks, technical level risk, management risk. A mong them, the external environ mental risk mainly refers to the natural environ ment and social environ ment changes may have the impact of the supply chain, technical level risk refers to the impact of big data disclosure and big data technology imperfections on supply chain operations, management risk includes more factors, including supplier management, supply chain cost management, customer relationship management and a series of supply chain internal management problems, but the precise marketing, whic $h$ is at the end of big data supply chain, requirements supplier de livery time and the level of logistics services can respond quickly, therefore, the two most risky management risk of big data supply chain should be the risk of suppliers and logistics congestion risk.

\section{An Analysis of the Risk Factors of Big Data Supply Chain}

After identifying these risk factors, the risk is analyzed in detail, and the potential threats to the supply chain are analyzed from the perspective of their source and mechanis $m$ to better implement the control strategy.

(1) External risks

External environmental risks from the social environment and the natural environment, they are all uncontrollable factors. Social turmoil may directly lead to the production of the supplier fracture and thus affect the smooth operation of the entire supply chain, the natural environment changes will lead directly to the delay in delivery, for the supply chain, natural environment changes are more likely to lead directly to loss of customers. Compared with other factors, the probability of occurrence of these uncontrollable factors is small, and difficult to predict, but it is enough to produce irreversible disastrous consequences of the supply chain, so that external risk is one of the main risks in big data supply chain.

\section{(2) Technical layer risk}

big data supply chain is based on the big data technology, the maturity of technology must mean that the efficiency of supply chain operation, mature technology is the most important means of cost reduction, at present, the development of large domestic data technology has crossed the initial stage, and data analysis technology is relatively mature, but because the supply chain member companies share the same big data platform, the risk of information disclosure is inevitable, when the core interests of member companies were violated, the supply chain is to the brink of rupture.

\section{(3) Management risk}

Fro $m$ the internal point of $v$ iew, big data supply chain management is more complex and sensitive, the application of big data technology change the majority of supplier management model of the supply chain which is extensive, Big data supply chain requires supplier management is multi-channel, two-way incentive, and common quality concept, therefore, for the entire supply chain, the supplier's type of risk is more abundant and volatile, the supplier will be perceived by other me mbers of the enterprise with slightly unstable. Detailed market partition requires the supply chain to have a fast response with a precise logistics system, and logistics is extremely difficult to control links, so the risk of logistics links highly threatening.

\section{Risk Control Strategy Based on Big Data}

\section{(1) Establish a big data suppliers risk response capacity index system}

Stable and sound supplier network is a prerequisite for the effective operation of the supply chain, it can't be ignored whether it is production-oriented enterprises or service-oriented enterprises are dependent on suppliers, the use of big data technology can effectively control the risk of suppliers, and help the supply chain keep stable when 
operating.

Big data supplier risk response capability system mainly includes the following: supplier production site status, supply production recovery capacity, supplier equipment flexibility, supplier - manufacturer communication, supplier quality management. If the enterprise fails to pass the result, it proves that there is a certain risk. The enterprise can control it accurately according to the identified risk to ensure the stable operation of the supply chain.

\section{(2) Implement the precise logistics risk control}

Logistics is one of the most uncertain factors in the process of supply chain operation. Logistics is the most difficult link to control in the supply chain. Mastering the control of logistics can effectively reduce the total cost of supply chain and improve its competitive strength. The use of big data technology can achieve accurate logistics control, reduce its risk factors.

Identify the safety risk of goods in transit is the application of big data technology, the use of RFID, GPS and other technologies to collect re levant data of goods in the transport, such as location weather data, cargo te mperature data, out of the box inspection times, transport routes data. These data back to the enterprise big data plat form, the enterprise, through the data in-depth mining analysis, can achieve the precise control of the logistics and avoid the risk factor in time. Big data on the precise control of logistics is particularly applicable to time-sensitive goods, it can play a significant role in the cold chain transport.

\section{(3) Predict the risk of supply chain breaks}

The supply chain rupture will cause irreversible loss to the enterprise, and the pre-fracture of the supply chain tends to show some signs, but the enterprises are ignoring these signs in order to chase the continuity of production, thus speeding up the pace of risk.

The risk of supply chain rupture is mainly due to the expansion of supply globalization and the change of social and natural environ ment. Enterprises can use the supplier's historical data and past environmental data to excavate the unstructured data which is difficult to master through the traditional data analysis technology. Big data analysis technology can achieve timely and accurate prediction of the production status of the supply source, understand the trend of environmental change and deal with these potential risks in a timely manner to prevent the emergence of a supply source fracture.

\section{(4) Identify outsourcing business and business outsourcing risk}

To maintain the core competitiveness of enterprises, enterprises tend to outsource non-core business, but non-core business generally contains many types, identify which non-core business needs outsourcing is the key to saving supply chain costs. The main risk of business outsourcing is the leakage of information within the enterprise. How to avoid this risk is also an important decision of the enterprise.

Big data analysis technology to identify the enterprise non-core business mainly through the development of detailed sub-outsourcing analysis strategy, clearly pointed out that the enterprise's own business capabilities and the ability of suppliers. In response to the risk of information disclosure, big data platform set different permissions for different enterpris es to ensure that the internal data will not be out of the loss.

\section{Conclusion}

The emergence of a new business is bound to be accompanied by many unknown risks, Big data has brought great changes to the supply chain, the risk of big data supply chain is also a threat to the steady operation of the supply chain. Supply chain members should clearly understand the existence of the risk, rather than blindly rely on big data technology to improve their own profits.

This paper studies the risk of big data supply chain by analy zing the operation mode of big data supply chain, and the purpose of the strategy is to help enterprises to avoid these risks when constructing big data supply chain, In the future research, the research on the risk of big data supply chain is also more deeply excavated from different angles such as forecasting, evaluation and transfer of risk management.

\section{Acknowledgments}

This paper was supported by "The Construction of Excellent Innovation Team of Philosophy and Social Science in Jiangsu Province”.

\section{References}

[1] Chen Ke-jia, Jin Lian, Lin Yue-kang. Optimal number of Suppliers under Supply Chain Dis ruption risk[J]. Industrial Engineering and Management. 2016,21(4): 80-85.

[2] FAN Xing, SHAO Ju-ping, SUN Yan-an. Risk Identification and Evaluation of Transnational Agricultural Product Supply Chain Based on Fuzzy Theory. Science and Technology Management Research [J]. 2016(6): 210-215.

[3] Nie Ru i-fang. supply chain risk and prevention under O2O model[J]. Journal of Commercial Economics. 2016(4): 
72-74.

[4] Sun Jinhua, Guo Xiang. Risk Factors Identification of Science and Technology Service Supply Chain Based on PAJEK Social Network Analysis Model[J]. Enterprise Economy. 2016(4): 89-93.

[5] YAN Jie, CHEN Wen, CHENG Xin, CHEN Guo-ying. Discussion on Enterprise Supply Chain Risk Management[J]. Logistics Engineering and Management. 2017(4): 105-107.

[6] Mu Jing Qi He. Risk and Prevention of Agricultural Products Supply Chain Based on Internet of Things [J]. Journal of Commercial Economics. 2017(6): 164-165. 